\title{
THE UNIVERSITY OF CHICAGO PRESS
}

\section{The Origin of the Earth. (The University of} Chicago Science Series.) By Thomas Chrowder Chamberitn, Head of the Department of Geology in the University of Chicago.

This book, by one of the leading geologists of the world, sets forth the disclosures that led to the rejection, one after another, of the older views of the origin of our planet, the futile attempts then made to emend these or to build others upon the same foundations, the final rejection of all these, and the construction of a radically new view based on a new dynamic foundation. The later chapters of the book treat of the early stages of the earth and of the way in which its leading processes took their start from their cosmogonic antecedents, these being held to be essential factors in the genesis of the planet. The beginning of the inquiry is set forth in the Introduction; the successive chapters are entitled: "The Gaseous Theory of Earth-Genesis in the Light of the Kinetic Theory of Gases"; "Vestiges of Cosmogonie States and Their Significance"; "The Deeisive Testimony of Certain Vestiges of the Solar System"; "Futile Efforts"; "The Forbidden Field"; "Dynamic Encounter by Close Approach"; "The Evolution of the Solar Nebula into the Planetary System"; "The Juvenile Shaping of the Earth"; "Inner Reorganization of the Juvenile Earth"; "Higher Organization in the Great Contact Horizons."

$$
\text { xii }+272 \text { pages, } 12 \mathrm{mo} \text {, cloth; } 6 \mathrm{~s} \text { net. }
$$

\section{Individuality in Organisms. (The University of Chicago Science Series.) By Charles Manning CHind, Associate Professor of Zoölogy in the Uni- versity of Chicago.}

Professor Child's work is an attempt to state, and to present evidence in support of, a conception of the nature of organic individuality which the author has developed as a result of fifteen years of investigation of the processes of reproduction and development in the lower animals. In these forms, organic individuality appears in relatively simple terms, and it is here that we must look for the key to the problem of individuality in the higher animals and man.

The author has addressed himself with remarkable success to showing the wide range of applicability of the conception of individuality of various fields, with the result that the book appeals not only to the physiologist and to the botanist, but also to the neurologist, to the psychologist, and even to the sociologist.

$$
\mathrm{x}+212 \text { pages, small } 12 \mathrm{mo} \text {, cloth; } 5 \mathrm{~s} \text { net. }
$$

\author{
The Cambridge University Press \\ Agents for the British Empire \\ London, Fetter Lane, E.C. 4
}


Stewart, F. H. On the Development of Ascaris lumbricoides and A. mystax in the Mouse. (With Plate IV) .

Stewart, F. H. On the Life History of Ascaris lumbricoides L.

Walton, Chas. L. Some Results of a Survey of the Agricultural Zoology of the Aberystwyth Area

Wation, Chas. L. Liver Rot of Sheep, and Bionomics of Limnaea truncatula in the Aberystwyth Area. (With 5 Text-figures)

Weidman, Fred D. A Contribution to the Anatomy and Embryology of Cladorchis (Stichorchis) subtriguetrus Rudolphi, 1814 (Fischoeder, 1901). (With Plate V and 2 Text-figures)

BAcot, A. A Note on the period during which the Eggs of Stegomyia fasciata (Aëdes calopus) from Sierra Leone Stock retain their vitality in a Humid Temperature

Warburton, CeciL. Notes on Ticks. (With 3 Text-figures) .

Nicold, Wrimam. On the Oecurrence of Hydatid Cysts in Monkeys

Nicolu, Wibiram. Dolichopera macalpini n. sp., a Trematode

Parasite of Australian Poisonous Snakes

Dobell, CltfFord. Are Entamoeba histolytica and Entamoeba ranarum the same Species?

PARASITOLOGY is published about four times a year. The numbers afterwards are issued in volumes each containing four numbers and amounting to about 500 pages, with plates and figures.

Papers for publication should be sent to Professor Geo. H. F. Notral, F.R.S., Longfield, Madingley Road, Cambridge. Other communications should be addressed to the University Press, Cambridge.

Papers forwarded to the Editors for publication are understood to be offered to PARASITOLOGY alone, unless the contrary is stated.

Contributors receive fifty copies of their papers free. Additional eopies, not exceeding one hundred (except in special cases), may be had at cost price : these should be ordered when the final proof is returned.

The subseription price is $£ 1$. 15s. per volume (post-free), payable in advance; single numbers $12 \mathrm{~s} .6 \mathrm{~d}$, net (double number $25 \mathrm{~s}$. net). Subseribers to the Journal of Hygiene may obtain single numbers of PARASITOLOGY at the reduced price of $10 \mathrm{~s}$. net, or may become subscribers at the reduced rate of $£ 1.5 s$. per volume. Subscriptions may be sent to any Bookseller, or to Mr C. F. OLAY, Manager, Cambridge University Press, Fetter Lane, London, E.C. 4.

The Cambridge University Press has appointed the University of Chicago Press agents for the sale of Parasitology in the United States of America and has authorised them to charge the following prices; Subscription $\$ 8.75$ net per volume; single numbers $\$ 3.25$ net each, double numbers $\$ 6.25$ net each. Subscribers to the Journal of Hygiene may obtain single numbers of Parasitology at the reduced price of $\$ 2.50$ net, or may become subseribers at the reduced rate of $\$ 6.25$ per volume.

The prices of back volumes are as follows:

Volumes I, II, III and IV (1908-11). Each volume in four parts, paper covers, 25s. net per volume. Bound in buckram, $30 \mathrm{~s}$, net per volume.

Volumes V, VI, VII, VIII and IX (1912-17). Each volume in four parts, paper covers, 35s. net per volume. Bound in buckram, 40s, net per volume.

Cases for binding volumes can be supplied at $3 s .6 d$. net each. 